\title{
Patient-and Family-Centered Care and Patient Safety: reflections upon emerging proximity
}

\author{
Cuidado Centrado no Paciente e Família e Segurança do Paciente: reflexões sobre uma proximidade emergente
}

Atención centrada en el paciente y la familia y la Seguridad del Paciente: reflexiones sobre una proximidad emergente

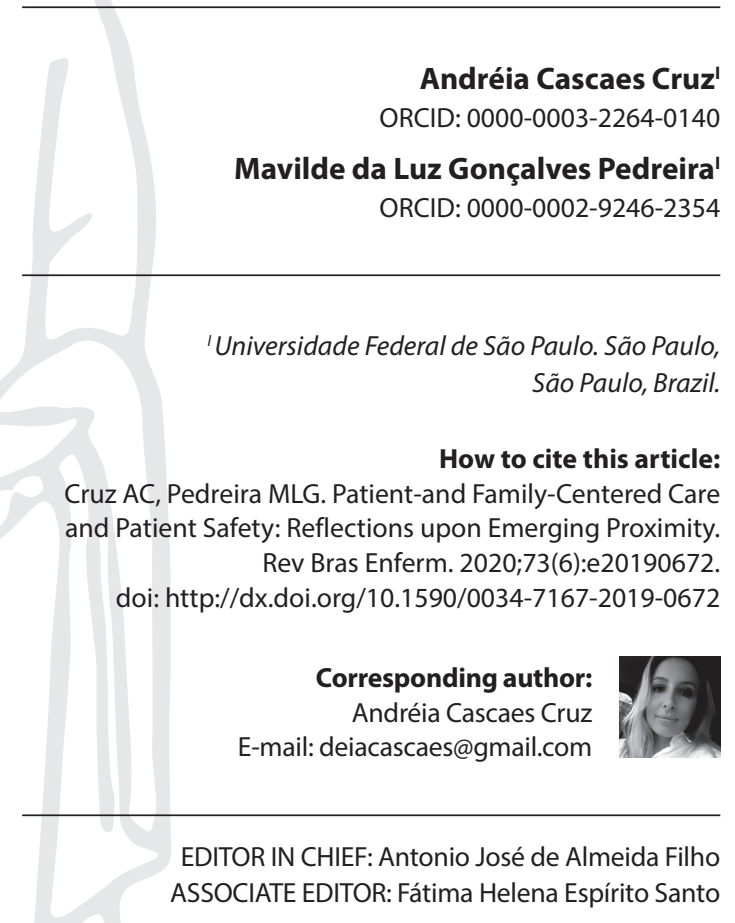

Submission: 23-09-2019

Approval: $30-03-2020$

\begin{abstract}
Objective: To present reflections upon conceptual and pragmatic relationships between the Patient-and Family-Centered Care and patient safety. Method: A discussion about constructs related to the Patient-and Family-Centered Care and patient safety, which shows their interface with pragmatic issues of clinical nursing practice. Results: Considering patients and families as partners and agents promoting safe care is mandatory for the safety culture. Final considerations: Decreasing errors and adverse health care events can be accomplished by understanding manners to incorporate the principles of Patient-and Family-Centered Care into issues related to patient safety.

Descriptors: Family Nursing; Patient Safety; Nursing Care; Patient-Centered Care; Quality of Health Care.
\end{abstract}

\section{RESUMO}

Objetivo: Apresentar reflexões sobre as relações conceituais e pragmáticas acerca do Modelo Cuidado Centrado no Paciente e na Família e da Segurança do Paciente. Método: Discussão acerca de construtos relacionados ao Modelo de Cuidado Centrado no Paciente e na Família e Segurança do Paciente apresentando a interface desses com questões pragmáticas da prática clínica de enfermagem. Resultados: Enfatiza-se ser imperativo à cultura de segurança considerar pacientes e famílias como parceiros e agentes promotores de um cuidado seguro. Considerações finais: Compreender formas de incorporar os princípios do Cuidado Centrado no Paciente e Família às questões relacionadas à segurança do paciente pode contribuir para mitigar erros e eventos adversos em saúde.

Descritores: Enfermagem Familiar; Segurança do Paciente; Cuidados de Enfermagem; Assistência Centrada no Paciente; Qualidade da Assistência à Saúde.

\section{RESUMEN}

Objetivo: Exponer reflexiones sobre las relaciones conceptuales y pragmáticas acerca del Atención centrada en el paciente y la familia y la Seguridad del Paciente. Método: Discusión acerca de construcciones relacionadas con Atención centrada en el paciente y la familia y la Seguridad del Paciente; presentando la interfaz de estos, con problemas pragmáticos de la práctica clínica de enfermería. Resultados: Se enfatiza ser imperativo a la cultura de seguridad, considerar pacientes y familias como colaboradores y agentes promotores de un cuidado seguro. Consideraciones finales: Comprender formas de incorporar los principios del Atención centrada en el paciente y la familia, a los problemas relacionados con la seguridad del paciente, puede contribuir para mitigar errores y eventos adversos en salud. Descriptores: Enfermería Familiar; Seguridad del Paciente; Cuidados de Enfermería; Asistencia Centrada en el Paciente; Calidad de la Asistencia en la Salud. 


\section{INTRODUCTION}

Patient safety is dedicated to the study of interactions occurring in the health care system that can result in errors and adverse events, in order to analyze, develop and re-evaluate the inclusion of strategies that mitigate the occurrence of health care-related failures. Patient-and Family-Centered Care (PFCC) is defined as an approach to health care planning, delivery, and assessment based on mutually beneficial partnerships among health care providers, patients, and families. The central construct of this care approach is partnership, which implies that nurses recognize equality among individuals involved in the care process (professionals, patients and families) ${ }^{(1)}$. Implementation of PFCC in care enacts several actions and strategies that can contribute to patient safety, by emphasizing the need for a relational practice based on partnership, the principles of dignity and respect, sharing of information, collaboration and participation ${ }^{(1)}$ as guidelines for institutional policies and professional practice.

\section{OBJECTIVE}

To present reflections upon conceptual and pragmatic relationships between the Patient-and Family-Centered Care and patient safety.

\section{CONCEPTUAL AND PRAGMATIC DISCUSSION}

First, let us consider that, even before patient safety achieved expressive visibility in health care, almost two decades ago, with the publication of To err is human: building a safer health care system, and before the formal definition of the PFCC model in 1987, an approximation between both ideas was identified in the Ottawa letter, published in 1986, when the World Health Organization (WHO) recognized the active participation of family in care, as a strategy for promoting the health of individuals.

Participation is the core concept in publications related to patient safety that consider PFCC as one of the vital strategies for promoting safe care. According to this model, the principle of participation includes providing support and encouragement to patients and families to participate in care and decision-making at the level they choose $\mathrm{e}^{(1)}$.

Great importance has been assigned on the participation of patients and families in initiatives for their own safety in the WHO Program Patients for Patient Safety (PFPS) ${ }^{(2)}$. This program is still one of the priorities in the health care area, whose proposal encourages families, health professionals and managers to work together in the development of action plans, policies and programs aimed at safety and the promotion of a culture of participatory learning.

We emphasize the proximity of the description above with the principle of collaboration outlined by the PFCC, which characterizes it as a collaborative process between health care professionals, managers and families in the development, delivery and evaluation of institutional policies and programs, health care facility planning, professional education process, as well as in the provision of patient care.

The interface between the family participation concept and issues related to patient safety was marginalized in government documents in Brazil, until the publication of the reference document for the National Patient Safety Program (NPSP) ${ }^{(3)}$ in 2014, when the involvement of patients and family members in patient safety actions was established as one of the goals.

However, no recommendations or guidelines are identified in the programs mentioned above that guide patients and families on how to be involved in the care practice in order to promote safe care. Patients and families are mainly seen as a learning resource when errors occur, than as active participants in the prevention of errors in the clinical practice.

Active involvement of the patient and family in care situations are recommended in the guide "Your Health Care - Be Involved" published by the Ontario Hospital Association $(\mathrm{OHA})^{(4)}$. According to this publication, patients and families are considered members of the health care team. The PFCC also recognizes patients and families as essential members of the health care team and essential to ensure quality and patient safety ${ }^{(5)}$.

By analyzing the OHA guide ${ }^{(4)}$, through the PFCC conceptual lens, it is possible to derive that shared information is the construct related to the recommendations, encouraging patients and families to obtain information about their diagnosis, treatment and prognosis, as well as to provide accurate information about their current and previous health status, and use of medication.

As advocated by the PFCC, information sharing involves communicating and exchanging complete, truthful, impartial and useful information with patients and their families in a timely manner, so that they can effectively participate in care and decision making ${ }^{(1)}$.

Studies show that one of the main needs of families experiencing illness and hospitalization is to receive information about the care delivered and health status of the patient ${ }^{(6-8)}$, and that, more and more families have been seeking information about the patient's health conditions online ${ }^{(9)}$. Therefore, it is important to reflect upon how this virtual information, often not evidence-based, can compromise aspects related to the safety of care, and how the lack of information sharing by health professionals with patients and families can lead them to access unsafe and low quality sources of information.

The following questions have arisen from the reflections above: Does the family have a voice to ask their questions? Do the professionals give voice to the family? What makes the family unable to question and talk about their needs? What prevents professionals from providing answers to the family needs? Therefore, families need to be empowered, and professionals must be skilled, so that questions are focused on the needs of the patients and their family, listening to them and meeting their demands.

We realize that if the answers to such questions were as simple as they seem, they would not be as complex to apply in practice. We will not always have all the answers to the questions of patients and families, and the answers will not always be precise; the Cartesian thinking does not extend to all questions of health and illness, nor to the situations of suffering experienced by patients and families. However, we believe that, the betterinformed patients and families are, the more they will be able to collaborate in promoting a safe care.

By using the concept of information sharing, we want to introduce the idea that failure to obtain information from the patient and family is a contributing factor to the occurrence of 
the error or adverse event. In contrast, sharing information can be a strategy both to prevent the error or the adverse event, and to understand the failures when they occur.

Although there is evidence that failure in interprofessional communication is one of the most common causes of adverse events in health care ${ }^{(10-11)}$, failure of professionals to communicate with the patient and family is barely associated with issues related to patient safety. Giving information to patients and families about their diagnosis, treatment and prognosis is considered a threatening situation by some professionals. They only give information they consider necessary, attributing to the institution the policy of not providing information to the patient. For nurses who have adopted such conduct, we recommend that their moral judgment of what is necessary, appropriate and important should be the basis for deciding what will be and when (if any) shared with the patient and family

Thus, a reflection is proposed on two aspects related to the same outcome, from different perspectives: How do health care professionals welcome the communication of information by the family that reveals itself as a health care related error? How do health care professionals report the occurrence of a health care-related error to the patient and family?

To the first question, we propose answers based on the symbolic meaning the family has for the health care professional. Whether he/she believes that the family is an essential member of the team and, consequently, a partner, the communication of an error by the family is understood as something constructive, which enacts early intervention and shows itself as a learning opportunity to review processes and mitigate future errors On the other hand, if the family is seen as an observer and judging element, the revelation of a mistake can be interpreted with hostility, which denotes lack of professional competence, implying inertia following the sharing of information.

Regarding the second question, reflection is proposed on three possible answers that reflect the absence of the PFCC principles in the professional actions: a first one in which the adverb "how" of the question would not be applicable, because professional silence would imply the non-disclosure of the error to the family; a second one in which some explanation would be given by the professional, in a quick and superficial manner, without providing an opportunity for a dialogue with the family; and a third one, in which the use of inappropriate language by the health care professional would make the communication of the error incomprehensible to the family.

Given the complexity of the systems and processes inherent to care practice, obtaining the collaboration of those who are the recipients of care and who have a privileged view of the situations experienced is an intelligent strategy for preventing errors. It is necessary to recognize that patients and families, provided with accurate information about the care and health status of the patient, and considered as partners and collaborators of the health care team, have much more chances to recognize failures in the care process than health care professionals, mainly because of the work overload and the shortage of human resources.

A study conducted in the pediatric setting found that families detected more errors and adverse events than health care professionals. Families identified communication failures as the main contributing factor to the occurrence of errors. Given these results, the study made recommendations that are directly in line with PFCC: a) to improve communication between physicians, nurses and families on safety issues; $b$ ) to consider families' knowledge; c) to actively involve families in the process of care supervision (to help prevent errors and/or identify them early); d) to involve families in care planning, to update them on changes, to encourage them to talk and participate (to be effective partners in preventing errors); e) to educate families on how to report possible errors.

Regarding pragmatic issues involving family participation and collaboration in patient safety during nursing care, we will return to the first global WHO challenge, which was oriented to the prevention and management of health care-associated infections (HAls) in health care services. Its focus has been on the practice of hand hygiene as a primary measure for infection prevention, with the theme Cleaner Care is Safer Care.

About this theme, a study showed that families, aware of the importance of hand hygiene and HAls, would accept invitations to participate in actions promoting hand hygiene. However, some family members reported the possibility of feeling uncomfortable when having to remind health care professionals about hand hygiene, reporting fear of a possible negative impact on the family-professional relationship. Regarding professionals' perceptions about this collaborative action with families, they also believed that such intervention by the family could impact negatively on the relationships between them and their families ${ }^{(13)}$.

Given the nurses' perception shown in the study above, a self-reflection on the family meaning for the professionals must be performed. We have already presented the conception of family as an observer and judging agent, but there are still some professionals who perceive them as an opponent. The fact is that these definitions, as well as considering patients and families incapable of contributing to the reduction of errors in health care, are restrictive beliefs that need to be modified. It is vital to the safety culture to consider patients and families as partners and agents for a safe care.

\section{FINAL CONSIDERATIONS}

The constructs discussed in this paper should be understood as a set of principles that guide the professional practice and, therefore, need to be absolutely present in any communication and relationship established with the patient and the family in the professional practice. When considering that health care professionals should also offer ethical care, based on the principles of autonomy, beneficence, non-maleficence and justice, and that these are intrinsically related to the principles postulated by the PFCC, their nullity in clinical practice may characterize an unethical care. Moreover, initiatives to promote the participation of patients and families in health care in our country may be much more frequent in the private sector than in the public one, because some are seen as consumers and others as merely "users" who benefit from free healthcare, and thus the possibility of errors are implicit.

As research advances, the approximation between PFCC and patient safety has been increasingly encouraged and gained prominence in different health care systems. Thus, it is necessary 
to think about the incorporation and articulation of the common concepts of PFCC and patient safety as professional competencies of nurses. The association of these two components in a grounded, conscious and intentional manner is capable of raising the level of care, promoting the provision of quality care that results in a better experience of the patient and family in contact with the health care system

As far as educational and health care institutions are concerned, it is necessary to recognize that the lack of training of health care professionals on establishing effective relationships with patients and family members is an obstacle to be surmounted, so that knowledge translation about the interface between the PFCC and patient safety can be accomplished.

\section{FUNDING}

Conselho Nacional de Desenvolvimento Científico e Tecnológico (CNPq).

\section{REFERENCES}

1. Davidson JE, Aslakson RA, Long AC, Puntillo KA, Kross EK, Hart J, et al. Guidelines for family-centered care in the neonatal, pediatric, and adult ICU. Crit Care Med. 2017;45(1):103-28. doi: 10.1097/CCM.0000000000002169

2. World Health Organization. Patients for Patient Safety: partnerships for safer health care [Internet]. Geneva, Switzerland: World Helath Organization; 2013[cited 2019 Sep 23]. Available from: https://www.who.int/patientsafety/patients_for_patient/PFPS_brochure_2013.pdf

3. Ministério da Saúde (BR). Programa Nacional de Segurança do Paciente [Internet]. Ministério da Saúde. 2014[cited 2019 Sep 23]. 42 p. Available from: http://bvsms.saude.gov.br/bvs/publicacoes/documento_referencia_programa_nacional_seguranca.pdf

4. Ontario Hospital Association. Patient Safety. Your health care - be involved [Internet]. Ontario; 2006[cited 2019 Sep 23]. Available from: https://www.oha.com/Documents/English Brochure - 2007.pdf

5. Dokken DL, Kaufman J, Johnson BH, Perkins SB, Benepal J, Roth A, et al. Changing hospital visiting policies: From families as "visitors" to families as partners. J Clin Outcomes Manag[Internet]. 2015 [cited 2019 Sep 23];22(1):29-36. Available from: https://www.mdedge.com/ jcomjournal/article/146722/practice-management/changing-hospital-visiting-policies-families-visitors

6. Santos LG, Cruz AC, Mekitarian FFP, Angelo M. Family interview guide: strategy to develop skills in novice nurses. Rev Bras Enferm. 2017;70(6):1129-36. doi: 10.1590/0034-7167-2016-0072

7. Alsharari A. The needs of family members of patients admitted to the intensive care unit. Patient prefer adherence [Internet]. 2019[cited 2019 Sep 23];13:465-73. Available from: https://www.dovepress.com/the-needs-of-family-members-of-patients-admitted-to-the-intensive-carepeer-reviewed-article-PPA

8. Foster M, Whitehead L, Arabiat D, Frost L. Parents' and staff perceptions of parental needs during a child's hospital admission: an Australian study. J Pediatr Nurs [Internet]. 2018[cited 2019 Sep 23];43:e2-9. Available from: https://linkinghub.elsevier.com/retrieve/pii/S0882596318300794

9. Pehora C, Gajaria N, Stoute M, Fracassa S, Serebale-O'Sullivan R, Matava CT. Are parents getting it right? a survey of parents' Internet use for children's health care information. Interact J Med Res [Internet]. 2015[cited 2019 Sep 23];4(2):e12. Available from: http://www.i-jmr.org/2015/2/e12/

10. Duarte SCM, Stipp MAC, Cardoso MMVN, Büscher A. Patient safety: understanding human error in intensive nursing care. Rev Esc Enferm USP [Internet]. 2018[cited 2019 Sep 23];52. doi: 10.1590/s1980-220x2017042203406

11. Bagnasco A, Tubino B, Piccotti E, Rosa F, Aleo G, Di Pietro P, et al. Identifying and correcting communication failures among health professionals working in the emergency department. Int Emerg Nurs [Internet]. 2013[cited 2019 Sep 23];21(3):168-72. Available from: https://linkinghub.elsevier.com/retrieve/pii/S1755599X12000924

12. Khan A, Coffey M, Litterer KP, Baird JD, Furtak SL, Garcia BM, et al. Families as partners in hospital error and adverse event surveillance. JAMA Pediatr [Internet]. 2017[cited 2019 Sep 23];171(4):372. Available from: http://archpedi.jamanetwork.com/article.aspx?doi=10.1001/jamapediatrics.2016.4812

13. Bellissimo-Rodrigues F, Pires D, Zingg W, Pittet D. Role of parents in the promotion of hand hygiene in the paediatric setting: a systematic literature review. J Hosp Infect [Internet]. 2016[cited 2019 Sep 23];93(2):159-63. Available from: https://linkinghub.elsevier.com/retrieve/pii/S01956701 1600092X 